\title{
The Correlation of Tuberculosis Smear Results and Immuno-suppression with CD4+ Counts as Surrogate Among HIV Infected Patients
}

\section{Kingsley Kamvuma*, Yusuf ademola, Warren Chanda, Michelo Miyoba, Sam Bezza Phiri, Christopher Newton Phiri and John Amos Mulemena \\ Mulungushi University, School of Medicine and Health Sciences, Zambia \\ *Corresponding Author: Kingsley Kamvuma, Mulungushi University, School of \\ Medicine and Health Sciences, Zambia.}

Received: October 07, 2021

Published: January 10, 2022

(C) All rights are reserved by Kingsley

Kamvuma., et al.

\begin{abstract}
Background: Human immunodeficiency virus (HIV) and M. tuberculosis are two intracellular pathogens that interact at the cellular, clinical and population levels. Since the recognition of AIDS in 1981, the number of reported cases of TB in the world has increased substantially, especially in regions with high incidence of AIDS. The main aim of this study was to establish whether there is a relationship between sputum smear positives and low CD4 cell counts among HIV infected patients.

Materials and Methods: This was a retrospective study involving 473 participants. The patients recruited in this study were those who tested HIV positive and smear positive for TB. Their HIV status was determined by performing an HIV blood test, if they were HIV positive their CD4 cell count were then made.

Results: This study examined the relation between smear positivity and low CD4 (below 200 cells/ $\mu$ l) together with CD8 and CD3 markers as a measure of immune function among patients infected with HIV. The study participants' constituted males $67 \%$ and females 33\%. The overall mean age was 33.2 (SD 6.9) with the youngest and oldest participants being 18 and 60 respectively. It was found that smear positive results negatively $(r=-0.13 ; p=0.021)$ correlated with CD4+ below 200 cells/ $\mu$ l. No correlation was observed between smear positives and CD8+ or CD3+ since the calculated correlation coefficient was not statistically 0.007 ( $p=0.9$ ) and $0.03(p=0.6)$ respectively. There were more $3+$ smear results below 200 cells/ $\mu$ l than the others while above 200 cells/ $\mu$ l $1+$ was the most commonly reported smear result. The scanty smear positives were the least commonly reported result in the low and high CD4 counts.
\end{abstract}

Conclusion: The smear positive result negatively correlated with a low CD4+ $(r=-0.13 ; p=0.021)$ but no correlation with low CD 8 and $C D+3$ results was observed. The long held theory that low bacillary counts in patients with low CD4+ counts needs to be revisited. The reduction of CD4+ cell count parallels' that of the total lymphocyte count and is more marked in patients with high bacillary counts. Further, studies are required to confirm these findings

Keywords: TB; HIV; CD4; Smear; Patients

\section{Abbreviations}

HIV: Human Immunodeficiency Virus; TB: Tuberculosis; PTB: Pulmonary Tuberculosis; WHO: World Health Organization; CD; Cluster of Differentiation, UTH; University Teaching Hospital; TDR: Tropical disease Research; HAART: Highly active antiretroviral Treatment; AFB: Acid fast Bacilli; CBH: Central Boad of Health; AIDS; Acquired immunodeficiency Syndrome

\section{Introduction}

Background

After decreasing throughout the twentieth century, the incidence of tuberculosis (TB) in the world increased in the late 1980s. The acquired immunodeficiency syndrome (AIDS) has played a central role in this increase. Since the recognition of AIDS in 1981, 
the number of reported cases of TB in the has increased substantially, especially in regions with high incidence of AIDS [1-3]. Onethird of the world's population is already infected with TB, with the greatest burden of the disease and infection borne by people in developing countries particularly high in sub Saharan Africa directly attributed to $20 \%$ increase in incidence, the region most affected by HIV/AIDS. It is estimated that less than half of all TB cases worldwide are diagnosed and fewer than $60 \%$ of diagnosed patients are cured. Projections of the future toll of the global TB pandemic are even more frightening. Without unprecedented efforts to improve TB control in regions hardest hit by the disease, the incidence are expected to increase steadily [4].

The alarming spread of Human immunodeficiency virus (HIV) and the emergence of drug resistance, tuberculosis (TB) is still out of control. The rate of breakdown to clinical TB much higher in patients co-infected with TB and HIV than those without TB [4]. Tuberculosis remains as the leading opportunistic infection and cause of death among HIV-infected subjects in resource-limited settings. The management of TB-HIV co-infection constitutes a great challenge for health care systems. Often, HIV infection is first detected when patients are diagnosed with active TB, and many such patients have advanced immune-suppression [5]. However, TB can also occur in individuals with relatively well preserved CD4 cell counts, especially in areas with high TB endemicity.

Complications of HIV are as a result of suppression of T Cell mediated immunity. T cell mediated immunity is important in defence of host against intracellular infections such as viral infections and some bacterial infections such as tuberculosis $[3,5]$. The constituents of the cell mediated immunity system include macrophages which present antigens to $\mathrm{T}$ cells; helper $\mathrm{T}$ cells participates in recognising antigens and regulatory functions; natural killer cells which inactivate pathogens and cyto-toxic $\mathrm{T}$ cells which can kill virus infected cells with or without antibodies. Both macrophages and helper $\mathrm{T}$ cells produce cytokines that activate or sensitize helper and cyto-toxic T cells to, kill pathogens or turmor cells [2].

A critical marker of immunologic integrity is the CD4 cell count, and the manifestations of tuberculosis vary with the CD4 cell count in HIV-positive patients with tuberculosis. As HIV infection progresses, CD4+ lymphocytes decline in number and function [3]. Therefore, the immune system is less able to prevent the growth and local spread of $M$. tuberculosis. As a result, the disease spreads to other parts of the body causing disseminated tuberculosis. Nevertheless, pulmonary TB the most common form of TB even in HIV infected patients since it occurs in $70-90 \%$ of all patients with TB [3]. The pathogenesis of both tuberculosis infection and the disease relates directly to cell mediated immunity (CMI) [6]. Especially CD4+ T lymphocytes. Not surprisingly, HIV infection which induces CD4+ T-lymphocytes depletion, also leads to defective immunological response to $M$. tuberculosis. The pathogenesis of TB can be altered by HIV either through reactivation of latent tuberculosis infection to active disease (more common) or by causing rapid progression from recent infection with $M$. tuberculosis to tuberculosis disease [7]. TB is an important cause of death in HIVinfected patients.

In Zambia 70\% of TB patients are HIV positive [8]. The country is currently estimated to have the ninth highest TB incidence in the world and an HIV prevalence of $14.3 \%$ countrywide, $22 \%$ in the capital, Lusaka [9]. Though some studies have been done on the relationship between these two infections at UTH more studies are required to find the best preventive strategies to counteract the effects of the two epidemics.

The frequent co-existence of TB and HIV the same individual implies the need to understand the associations of TB and HIV clearly and manage both conditions simultaneously. Patients with low CD4+ count have high risk of mortality and morbidity [10]. TB can occur in both HIV negative and positive patients but Infection with HIV has increased the incidence of TB since it activates dormant TB. TB can be treated if prescribed therapy is followed properly. The major problems in treatment of TB infections include lack of compliance to prescribed drugs by patients and development of resistance against anti-TB.

\section{Methodology}

\section{Study site and population}

This study was conducted from WHO/TDR TB-HAART Project at Adult Infectious Disease Centre a research institution located within the University Teaching Hospital (UTH). The study was a retrospective study design conducted from October, 2010 to march, 2011. The data was obtained from the database dating back from 2008 to February, 2011.

The project recruited 473 participants and a purposive sampling method was used to include participants in the study. The 
sample size was arrived at after taking into consideration the resources available, labour, transport and the limited time period available in which the project was to be done.

\section{Recruitment settings}

Both males and females between 16-60 years were to be recruited in this study and accessed from various clinics around Lusaka.

- Eligibility criteria: Patients were eligible to participate in the study if they tested HIV positive; have tested smear positive for tuberculosis and consented to be included in the study.

- Exclusion criteria: Participants were excluded if they either have not tested smear positive for tuberculosis or are not HIV positive.

\section{Data collection}

The patients who were recruited in this study are those who are HIV positive and test smear positive for TB. They were either admitted to in their various clinics or send home after being given drugs and come for continuous monitoring from time to time to obtain their CD4 cell count and for a drug refill. Their HIV status was determined by performing an HIV blood test, if they tested HIV positive their CD4 cell count was then be made. Diagnosis of TB was made by microscopic examination, using fluorochrome stain to demonstrate the presence of tubercle bacilli bacteria from sputum specimens in the TB laboratory and count the number of AFB per oil immersion field. All the results were recorded for analysis.

\section{Laboratory procedures}

- Venous blood was collected into EDTA containers for CD4 counts using the BD FACSCalibur in the Virology Laboratory. Blood samples for HIV testing were collected in plain containers for HIV testing.

- The national HIV testing Algorithm which uses Abbot Determine and Unigold as first line tests and SD Bio-line as a tie breaker was be followed. All specimens that were reactive for Abbot Determine were then confirmed with Unigold and if any such specimens tests differently on the Unigold, Bio-line was used as a tie breaker. The results of the Bio-line were then accepted as final.

- For enumeration of CD4 T Lymphocytes flow cytometry the BD FACSCalibur was utilised.
- Detection of TB was be done by microscopic demonstration of tubercle bacilli tuberculosis from sputum smears that was be obtained from the patients who were HIV positive.

Data analysis

All collected data was entered onto computer and spss version 16 software was used for analysis. Graphs, table, cross tables, means and correlation coefficient were calculated. The test of association between variables and factors was used for analysis and probability values were used for statistical significance.

\section{Ethical considerations}

- Authorisation to conduct the project in virology and the TB laboratories was obtained from the Hospital management before embarking on the project. Authorisation to use the data from adult infectious disease centre was also obtained.

- With respect to patient confidentiality the information obtained from each participant will not be published. Anonymity of patients was be ensured since names, physical address or any other identity or contact details will not be obtained and test results will not be identified with a particular participant. Each specimens will be identified by use of codes.

\section{Results}

Demographic description of the study population

A total of 473 participants who were both sputum positive and HIV positive were recruited into the study, 317 (67\%) being males and 156 (33\%) females with the youngest and oldest participant being 18 and 60 years of age respectively. The overall mean age was 33.2 years (SD 7.1years). The females were younger (mean age 32( SD 8) years) than males (mean age 34 (SD 6)years). These demographic profiles are given in table 1.

\begin{tabular}{|l|c|c|c|c|c|}
\hline & Number & $\begin{array}{c}\text { Minimum } \\
\text { age }\end{array}$ & $\begin{array}{c}\text { Maximum } \\
\text { age }\end{array}$ & Mean & $\begin{array}{c}\text { Std. } \\
\text { Devia- } \\
\text { tion }\end{array}$ \\
\hline $\begin{array}{l}\text { All the } \\
\text { patients }\end{array}$ & 473 & 18 & 60 & 33.20 & 7.117 \\
\hline Males & 317 & 18 & 58 & 33.79 & 6.414 \\
\hline Females & 156 & 20 & 60 & 31.97 & 8.271 \\
\hline
\end{tabular}

Table 1 
Figure 1 below shows the age of participants recruited into the study. The majority of TB/HIV CO-infected patient were in the 25 to 40 years age group, the age group with high incidence of HIV infection.

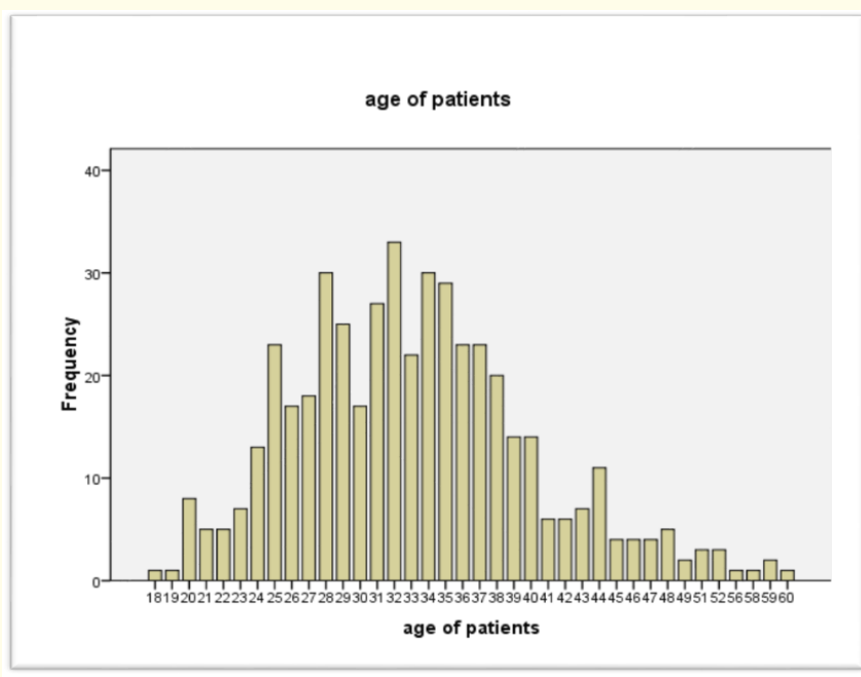

Figure 1

Laboratory characteristics of the study population

As shown in table 2a the mean CD4 cell count for the 473 patients was $185.0 \pm 183$ cells/ $\mu$ l. 343 (72.5\%) patients had low CD4 cell count (below 200 cells/ $\mu$ ), and 130 (27.5\%) patients had a high CD4 cell counts (above 200 cell/ $\mu \mathrm{l}$ ), The CD8 cell count was lower in patients with low CD4 cell counts (mean CD8 672.7 cells/ $\mu$ ) (see table $2 \mathrm{~b}$ ) than in patients with high CD4 cell counts (mean CD8 967.6 cell/ $\mu$ l) (see table $2 \mathrm{c}$ ). The CD3 T lymphocyte count was also lower in patients with low CD4 cell counts (mean CD3 823.7cells $/ \mu \mathrm{l}$ ) than in patients with high CD4 cell counts (mean CD3 1466.2cells/ $\mu$ ).

\begin{tabular}{|l|c|c|c|c|c|}
\hline \multicolumn{6}{|c|}{ The table describes the overall results for CD4, CD8 and CD3 } \\
\hline & $\mathbf{N}$ & Minimum & Maximum & Mean & $\begin{array}{c}\text { Std. } \\
\text { Deviation }\end{array}$ \\
\hline $\begin{array}{l}\text { CD4 } \\
\text { results }\end{array}$ & 469 & 2 & 1101 & 183.91 & 183.224 \\
\hline $\begin{array}{l}\text { CD8 } \\
\text { results }\end{array}$ & 469 & 48 & 3016 & 752.37 & 484.050 \\
\hline $\begin{array}{l}\text { CD3 } \\
\text { results }\end{array}$ & 469 & 87 & 3500 & 999.02 & 642.184 \\
\hline $\begin{array}{l}\text { Valid N } \\
\text { (listwise) }\end{array}$ & 469 & & & & \\
\hline
\end{tabular}

Table 2a

\begin{tabular}{|l|l|c|c|c|c|}
\hline \multicolumn{7}{|c|}{ The table describes statistically the results with CD4 below } \\
200 cells/ $\boldsymbol{\mu l}$ \\
\hline & N & Minimum & Maximum & Mean & $\begin{array}{c}\text { Std. } \\
\text { Deviation }\end{array}$ \\
\hline $\begin{array}{l}\text { CD4 } \\
\text { results }\end{array}$ & 341 & 2 & 200 & 99.42 & 60.981 \\
\hline $\begin{array}{l}\text { CD8 } \\
\text { results }\end{array}$ & 341 & 48 & 3016 & 672.74 & 452.121 \\
\hline $\begin{array}{l}\text { CD3 } \\
\text { results }\end{array}$ & 341 & 87 & 3500 & 823.66 & 529.534 \\
\hline $\begin{array}{l}\text { Valid N } \\
\text { (listwise) }\end{array}$ & 341 & & & & \\
\hline
\end{tabular}

Table 2b

\begin{tabular}{|l|c|c|c|c|c|}
\hline \multicolumn{7}{|c|}{ The table describes statistically the results with CD4 above } \\
\hline & N & Minimum & Maximum & Mean & $\begin{array}{c}\text { Std. } \\
\text { Deviation }\end{array}$ \\
\hline $\begin{array}{l}\text { Cd4 } \\
\text { results }\end{array}$ & 128 & 201 & 1101 & 408.99 & 208.630 \\
\hline $\begin{array}{l}\text { Cd8 } \\
\text { results }\end{array}$ & 128 & 214 & 2000 & 964.52 & 503.770 \\
\hline $\begin{array}{l}\text { Cd3 } \\
\text { results }\end{array}$ & 128 & 549 & 3500 & 1466.17 & 683.009 \\
\hline $\begin{array}{l}\text { Valid N } \\
\text { list- } \\
\text { wise) }\end{array}$ & 128 & & & & \\
\hline
\end{tabular}

Table 2c

The relationship between CD4 cell counts and smear positive result for tuberculosis was analysed using correlations. To describe the strength of association between variables the Pearson product moment coefficient was utilised for analysis. There was a negative correlation between the smear results and CD4 cell counts below 200 cells $/ \mu \mathrm{l}(\mathrm{r}=-0.13, \mathrm{P}=0.021)$. The negative sign implies that high scores on one variable is associated with low scores on the other. There was no correlation between smear results and CD8 or CD3 since the calculated correlation coefficient was 0.007 for CD8 $(\mathrm{p}=0.9)$ and 0.03 for $\mathrm{CD} 3(\mathrm{p}=0.6)$ respectively.

In table 4 the strong positive correlation indicates that the lower CD4 correlates with lower CD3 and higher CD4 correlates with higher CD3. 


\begin{tabular}{|c|c|c|c|c|c|}
\hline \multicolumn{6}{|c|}{ Correlations for smear positives and low CD4 (below 200 cells/ $\boldsymbol{\mu l}$ ) } \\
\hline & & Smear results & CD4 results & CD8 results & CD3 results \\
\hline \multirow{3}{*}{ Smear results } & Pearson Correlation & 1 & $-.125^{*}$ & .007 & .027 \\
\cline { 2 - 6 } & Sig. (2-tailed) & & .021 & .900 & .620 \\
\cline { 2 - 6 } & $\mathrm{N}$ & 343 & 343 & 341 & 341 \\
\hline \multicolumn{7}{|c}{ *. Correlation is significant at the 0.05 level (2-tailed). } & & \\
\hline
\end{tabular}

Table 3

\begin{tabular}{|c|c|c|c|}
\hline \multicolumn{4}{|c|}{ Correlations } \\
\hline & & Cd4 results & Cd3 results \\
\hline \multirow{3}{*}{ CD4 results } & Pearson Correlation & 1 & $.572^{* *}$ \\
\hline & Sig. (2-tailed) & & .000 \\
\hline & $\mathrm{N}$ & 473 & 469 \\
\hline \multirow{3}{*}{ CD3 results } & Pearson Correlation & $.572^{* *}$ & 1 \\
\hline & Sig. (2-tailed) & .000 & \\
\hline & $\mathrm{N}$ & 469 & 469 \\
\hline **. Corr & lation is significant at & he 0.01 level & -tailed). \\
\hline
\end{tabular}

Table 4: The shows the correlation of CD4 results and CD3 results.

Figure 2 below shows the most commonly reported smear result for patients with low CD4 cell counts (below 200 cell/ $\mu \mathrm{l}$ ). As can be seen the smear result of $3+$ is the most commonly reported result with a frequency 120 of 343 representing $25.4 \%$. It is followed by $1+$ with a frequency 104 of $343(22 \%)$, smear result of $2+$ had frequency of 95 of 343 (20\%) and the smear results reported as less than $1+$ was the least reported result with a frequency only 24 of $343(5.1 \%)$.

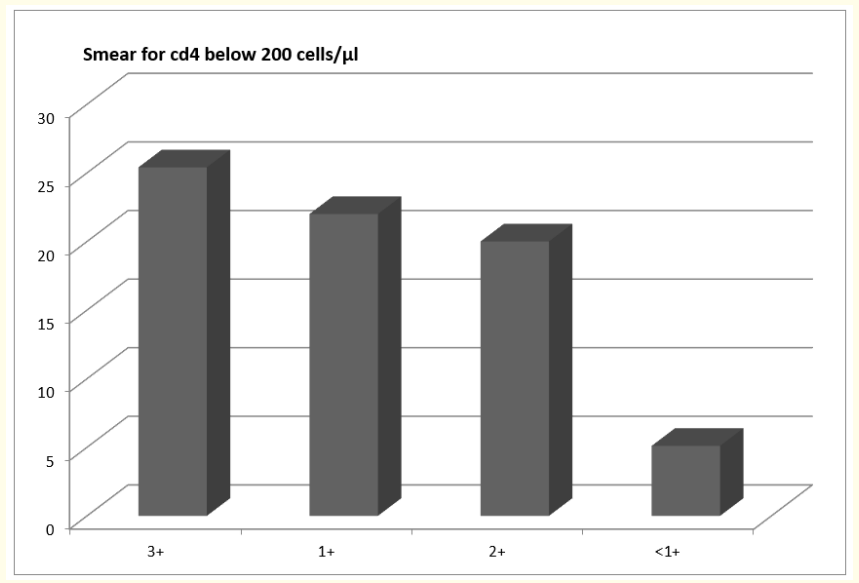

Figure 2
In figure 3 shown below the smear results reported for patients with high CD4 count (above 200 cell/ $\mu \mathrm{l}$ ) were presented on a frequency table to find the most frequently and least reported result. We can see that a smear result of $1+$ with a frequency 40 of 130 results $(30.8 \%)$ is the most commonly reported while the least commonly reported result was for less than $1+$ with 24 of 130 results (18.5\%).

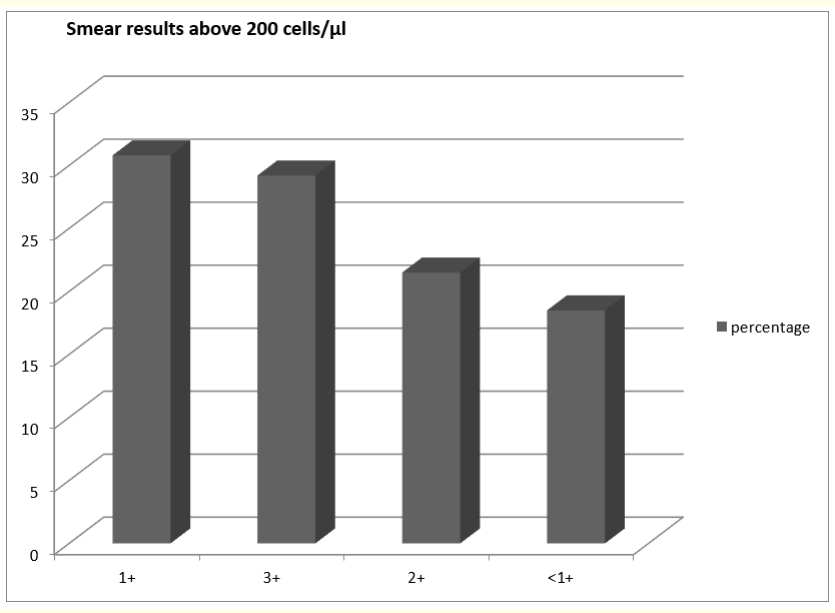

Figure 3

\section{Discussion}

Human immunodeficiency virus (HIV) and M.tuberculosis are two intracellular pathogens that interact at the cellular, clinical and population levels. Mounting immunologic and virologic evidence indicates that the host immune response to $M$. tuberculosis enhances HIV replication and accelerate the progression of HIV infection [11]. Therefore, understanding the interaction between these two pathogens at cellular level will have important implications on disease progression and treatment. If MTB multiplies there will more MTB which the immune system has contain, enhancing further viral replication which infects and destroys more CD4 T cells [1]. As 
was shown in this study a low CD4 count was associated with high smear count for tuberculosis among patients with HIV. There is a negative correlation between the sputum smear results and CD4 cell count ( $r=-0.13, p=0.021$ ) though the strength of association was not significant. This implies that a high positivity result such as $3+$ result correlates with lower values of CD4 cell counts.

The lack clear correlation can be attributed to factors apart from HIV infection and TB disease that may affect CD4 cell count. In fact, in one particular study it was reported that in patients with HIV infection, the frequency of positive acid-fast smears was independent of CD4 cell counts [12]. To illustrate the reason for this; if we have two patients both affected by TB/HIV, the first patient receives moral support from family, friends, support groups etc and financially stable to afford a balanced diet and the second patient is facing stigma from family and friends and because of poverty cannot afford a meal or hospital bills [13]. The first patient will have a raise CD4+ cell count compared to the second patients at same stage of tuberculosis disease. Two important factors can attributed to this; psychological stress further depresses the immune system and lack of a balanced diet to boast the immune system leads to further reduction of the immune system's strength.

In addition to these factors which affect the CD4 cell counts many factors influence the distribution sputum smear results apart from the extent of tuberculosis disease. These may include the quality of the sputum produced, use of compromised stains or a poor staining technique, the integrity of the microscope's optical system, or the amount of time spent on examination [14]. Therefore, a multitude of factors thus influences the reported sputum smear result. This study has indicated that scanty positive results are the least commonly reported result in both low and high CD4 counts this may because be Low bacillary counts are more difficult than higher counts to find in microscopic sputum examination, and if less time is spent examining them, they are more likely to be missed.

There is no correlation between sputum smear results and CD8 of $(0.007, p=0.9)$. This is consistent with the results of a study in which the relationship between laboratory presentation of TB and CD4 cell counts was investigated. They found that CD8 cell counts did not correlate with the manifestations of tuberculosis [15]. CD3 also did not correlate with smear results.
Patients with disseminated tuberculosis disease have a general increase in organism burden and, specifically, to the lung's place as the original site of infection [12]. This suggests that these patients will have a high sputum smear result i.e. $3+$ because of the of the increase orgarnism burden. Because of increase in the burden of MTB their CD4 there will be further depressed this observation is consistent with findings of this study since $25.4 \%$ of patients with CD4 below 200 cells/ $\mu$ l reported smear result of $3+$ compared to $5.1 \%$ reported for those with smear result of $<1+$.

\section{Recommendations}

The prevalence TB/HIV co-infection is high in the country. The co-existence the two infections in the same individual requires management of both diseases simultaneously. Therefore, understanding them at cellular, clinical and population level will help to generate strategies to prevent, improve diagnosis and treatment or treat the two infections simultaneously. With such potential benefits to medicine, it is recommended that stakeholders such as adult infectious disease research centre or the ministry of health to implement a study on a large scale.

Severity of tuberculosis disease cannot be determined by smear results only, hence a study related to this one must take into consideration other factors which help in diagnosis and determine the extent of tuberculosis disease i.e. culture, $\mathrm{X}$ ray, BMI etc.

It has been noted from this study that scanty smear positives were the least commonly reported result in both low and high CD4 cell counts. This has been attributed to less time spent examining the specimens. This can be avoided by ensuring that procedures or standards followed properly before a smear can be reported as negative.

During the study it observed that negative sputum smear results had depressed CD4+ T lymphocytes and total T lymphocytes counts. This may because an infection viral or bacterial other than Mycobacterium tuberculosis causing the depression. Despite $M$. Kansasii being antigenically and clinically related to M. Tuberculosis (Bloch KC., et al. 1998), very little information is available on the it's impact, mechanism of immune evasion and on what constitutes a protective immune response against it. A study is highly recommended which will determine what causes low CD4 cell counts in HIV positive patients with negative smear result for tuberculosis but with signs and symptoms similar to tuberculosis disease. 


\section{Conclusion}

The smear positive result negatively $(r=-0.13, \mathrm{p}=0.021)$ correlated with a low cd4 but no correlation with low CD8+ and CD3+ results was observed. The long held theory that low bacillary counts in patients is associated with low CD4+ counts needs to be revisited. Many factors influence CD4+ counts these include socioeconomic factors or may be due to an underlying disease e.g. a parasitic infection such as malaria, or may be as a result of technical incompetences. The reduction in CD4 cell count parallels' that of the total lymphocyte count and is more marked in patients with severe tuberculosis. A high smear count of $3+$ is the most commonly reported result for patients with $\mathrm{CD} 4$ below 200 implying that the lower the CD4 count the higher the organism burden while 1+ was most commonly reported in higher CD4 counts.

\section{Ethical Considerations}

The study was approved by the University of Zambia, Biomedical Research Ethics Committee (UNZABREC).

\section{Competing Interest}

The authors declares that they have no competing interest.

\section{Funding}

The authors conducted the study without external funding.

\section{Authors' Contributions}

$\mathrm{KK}$, conceived and designed the study. KK and SBP collected the data. KK was responsible for coordination and implementation of study. JAM, WC, MM, SBP, YA, CNP and KK conducted data analysis and article writing. All authors read and approved the final manuscript.

\section{Data Availability}

Data for this study will made available upon request.

\section{Consent for Publication}

All the authors have read and approved submission of this research article.

\section{Bibliography}

1. K C Bloch., et al. "Incidence and clinical implications of isolation of Mycobacterium kansasii: results of a 5-year, population-based study". Annals of Internal Medicine 129.9 (1998): 698-704.
2. N Caccamo., et al. "Multifunctional CD4 (+) T cells correlate with active Mycobacterium tuberculosis infection". European Journal of Immunology 40.8 (2010): 2211-2220.

3. G J Pontororing., et al. "The burden and treatment of HIV in tuberculosis patients in Papua Province, Indonesia: a prospective observational study". BMC Infectious Diseases 10.1 (2010): 362.

4. Sarder Nasir Uddin., et al. "Consequence on Treatment of TB Patients Affected by HIV/AIDS A Conceptual Research". American Journal of Infectious Diseases 2.4 (2006): 210-218.

5. C K Kwan and J D Ernst. "HIV and Tuberculosis: a Deadly Human Syndemic". Clinical Microbiology Reviews 24.2 (2011): 351-376.

6. B E Jones., et al. "CD4 Cell Counts in Human Immunodeficiency Virus-Negative Patients with Tuberculosis". Clinical Infectious Diseases 24.5 (1997): 988-991.

7. A Jaryal., et al. "Manifestations of tuberculosis in HIV/AIDS patients and its relationship with CD4 count". Lung India 28.4 (2011): 263-266.

8. Ministry of Health. "2009 Annual Health Statistical Bulletin". Ministry of Health Zambia (2011).

9. “Home" (2022).

10. Z Toossi., et al. "Impact of tuberculosis (TB) on HIV-1 activity in dually infected patients". Clinical and Experimental Immunology 123.2 (2009): 233-238.

11. S S Abdool Karim., et al. "HIV infection and tuberculosis in South Africa: an urgent need to escalate the public health response". Lancet 374.9693 (2009): 921-933.

12. R L Smith., et al. "Factors affecting the yield of acid-fast sputum smears in patients with HIV and tuberculosis". Chest 106.3 (1994): 684-686.

13. J S Sutherland., et al. "Polyfunctional CD4 (+) and CD8 (+) T cell responses to tuberculosis antigens in HIV-1-infected patients before and after anti-retroviral treatment". Journal of Immunology 184.11 (2010): 6537-6544.

14. G Sussman and A A Wadee. "Production of a suppressor factor by CD8+ lymphocytes activated by mycobacterial components". Infection and Immunity 59.8 (1991): 2828-2835. 
15. AM Elliott., et al. "The impact of HIV on infectiousness of pulmonary tuberculosis: a community study in Zambia”. AIDS 7.7 (1993): 981-987.

\section{Assets from publication with us}

- Prompt Acknowledgement after receiving the article

- Thorough Double blinded peer review

- Rapid Publication

- Issue of Publication Certificate

- High visibility of your Published work

Website: www.actascientific.com/

Submit Article: www.actascientific.com/submission.php

Email us: editor@actascientific.com

Contact us: +919182824667 